Article

\title{
Regulation of Spraying 6-BA in the Late Jointing Stage on the Fertile Floret Development and Grain Setting in Winter Wheat
}

\author{
Shengnan $\mathrm{Li}^{1,2,3}$, Miao Song ${ }^{1,3}$, Jianzhao Duan ${ }^{1,2,3}$, Jiaheng Yang ${ }^{1,3}$, Yunji Zhu ${ }^{1,2,3, *}$ \\ and Sumei Zhou $1,3, *$ \\ 1 The College of Agronomy, Henan Agricultural University, Zhengzhou 450046, China; \\ 15738818490@stu.henau.edu.cn (S.L.); 15003803253@stu.henau.edu.cn (M.S.); \\ djz20008@stu.henau.edu.cn (J.D.); Yangjiaheng@stu.henau.edu.cn (J.Y.) \\ 2 The National Engineering Research Centre for Wheat, Henan Agricultural University, \\ Zhengzhou 450046, China \\ 3 National Key Laboratory of Wheat and Maize Crop Science, Henan Agricultural University, \\ Zhengzhou 450046, China \\ * $\quad$ Correspondence: hnndzyj@henau.edu.cn (Y.Z.); nxyzsm@henau.edu.cn (S.Z.); Tel.: +86-138-3809-7937 (Y.Z.); \\ +86-135-9808-9865 (S.Z.)
}

Received: 10 July 2019; Accepted: 9 September 2019; Published: 12 September 2019

check for updates

\begin{abstract}
Wheat yield is largely determined by the grains per spike, which in turn is related to the fertile floret development prior to anthesis. The aim of this study was to assess the physiological mechanism of exogenous 6-benzylaminopurine (6-BA) on fertile floret development and grain setting characteristics by foliar application in winter wheat. Field experiments were conducted during the 2016-2017 and 2017-2018 growing seasons in China. Two foliar spraying applications with water (S0) and 6-BA (S1) were applied to a large-spike variety (V1) and a multiple-spike variety (V2) 25 days after jointing. At anthesis, spike dry weight and soluble sugar, sucrose, auxin, and cytokinin were all positively correlated with the number of fertile florets and grains per spike. During the abortion stage of fertile florets, 6-BA application compared to the control reduced the auxin content, increased the cytokinin content and spike dry matter and transported more soluble sugar and sucrose from the non-spike organs to the spike. Exogenous 6-BA application increased the number of fertile florets ( $\sim 1.84$ to $\sim 2.50)$ and number of grains ( $\sim 2.83$ to $\sim 3.51)$ by primarily suppressing the number of degenerated and aborted florets. The results provide important evidence that 6-BA application has a positive effect on floret fertility and grain setting, which lead to a further increase in grain yield.
\end{abstract}

Keywords: winter wheat; exogenous cytokinin 6-BA; fertile floret; grain number per spike; dry weight; sugar; hormone

\section{Introduction}

In recent years, the decreasing farmland and burgeoning world population means that a substantial increase in grain yield is needed, posing a challenge to food security [1-3]. As one of three main food crops, wheat (Triticum aestivum L.) has been widely cultivated throughout the world. Studies on how to achieve a higher yield are extremely important for ensuring global food security [4-6]. Wheat grain yield is determined by its components including spike number per unit area (SN), grain number per spike (GN), and thousand-grain weight (TGW), and the increased coordination between yield components is the key to a high yield [7,8]. Studies have shown that the SN has reached saturation in practice [9], and the TGW is already at a high level due to the genetic characteristics of cultivars [10]. 
However, GN still has great potential to increase and thus constitutes a breakthrough point to achieve a continuous increase of yield [11].

GN in wheat is largely dependent on floret development during the pre-anthesis stage as a result of the intricate processes of floret generation, degeneration and abortion [12,13]. A previous study found that 180 floret structures are generated per plant in wheat, which later become fertile and capable of bearing grains, but only $20 \%$ of them could eventually develop into grains [14]. Thus, there is a high potential to increase the GN in wheat. Based on the fact that the number of fertile florets directly determines the GN, and the number of fertile florets is most frequently determined by the survival of florets rather than by the number of florets produced, reducing the degeneration and abortion of florets can promote increasingly florets survive to fertile florets, thus leading to an increase of the GN [15-17]. Studies have found that the number of fertile florets is influenced by the environment, nutrients, and endogenous hormones during the abortion stage of fertile florets in wheat. The regulation of endogenous hormones may effectively increase the survival rate of florets [17-20]. Previous studies have shown that cytokinin effectively controls plant growth and development by regulating the proliferation and differentiation of plant cells, such as promoting bud growth and fruit development, delaying senescence, and regulating the transduction of nutritional signals [21-23]. 6-benzylaminopurine (6-BA) is a synthetic cytokinin that can also promote cell division and improve plant growth and development [24]. Applying exogenous 6-BA alters the endogenous hormone level in wheat, increases glutamine synthetase (GS) activity and protein content in grains, enhances antioxidant capacity and photosynthetic performance $[25,26]$. Spraying application of 6-BA before anthesis may promote the accumulation of dry matter in plants and its distribution to grain organs, thus increasing the yield [27].

The effects of 6-BA on the abortion of fertile florets during key stages of grain setting in winter wheat are rarely studied. Therefore, this study is focused on the abortion stage of fertile florets. The objective of the present work was to study the effects of exogenous 6-BA on fertile floret development and grain setting characteristics by foliar spraying application in winter wheat at 25 days after jointing. The results may provide a theoretical basis and technical guidance for further increases in grain yield.

\section{Materials and Methods}

\subsection{Experimental Materials and Design}

Field experiments were conducted in the Science and Education Demonstration Park of Henan Agricultural University $\left(113^{\circ} 59^{\prime} \mathrm{E}, 34^{\circ} 86^{\prime} \mathrm{N}\right)$ during the 2016-2017 and 2017-2018 growing seasons. The soil type was loam with the following basic chemical properties at $0-20 \mathrm{~cm}$ depth cultivated layer: $16.0 \mathrm{~g} \mathrm{~kg}^{-1}$ organic matter, $0.95 \mathrm{~g} \mathrm{~kg}^{-1}$ total nitrogen, $115 \mathrm{~g} \mathrm{~kg}^{-1}$ available nitrogen, $21.6 \mathrm{~g} \mathrm{~kg}^{-1}$ available phosphorous, and $95 \mathrm{~g} \mathrm{~kg}^{-1}$ available potassium. All experimental plots were fertilized with $180 \mathrm{~kg} \mathrm{ha}^{-1}$ nitrogen (using urea, $\left.46 \%\right), 150 \mathrm{~kg} \mathrm{ha}^{-1}$ phosphate $\left(\mathrm{P}_{2} \mathrm{O}_{5}\right)$, and $150 \mathrm{~kg} \mathrm{ha}^{-1}$ potash $\left(\mathrm{K}_{2} \mathrm{O}\right)$. Fifty percent of the nitrogen fertilizer was applied before sowing, and the same quantity was applied in the jointing stage. Phosphate and potash fertilizers were all applied before sowing as a base fertilizer. The growth and development of the wheat plants were managed according to common high-yielding field conditions.

The experimental varieties used in this study were a large-spike variety, Zhoumai 16 (V1), and a multiple-spike variety, Yumai 49-198 (V2). The wheat was sown on 12 October in both years, at a density of 225 plants $\mathrm{m}^{-2}$ in 12 rows in each plot with an equal row spacing of $20 \mathrm{~cm}$. At 25 days after jointing (before the abortion of fertile florets), foliar spraying was applied with water (No spraying 6-BA treatment, S0) and $10 \mathrm{mg} \cdot \mathrm{L}^{-1}$ 6-BA (Spraying 6-BA treatment, S1). The amount of 6-BA sprayed was controlled following the protocol described by our previous study [15], which claim to form a layer of mist on the leaf surface without liquid dripping down. The experimental design was a split-plot design with each treatment repeated three times. The plot size was $20.3 \mathrm{~m}^{2}(2.9 \times 7 \mathrm{~m})$, and the 6-BA and control treatments were equal of every plot. 


\subsection{Measurements and Methods}

\subsubsection{Observations of Young Spike Development in Wheat}

Three wheat plants with uniform growth were obtained every three days for each treatment from foliar application with water and 6-BA at the late jointing stage to five days after anthesis. The differentiation stage of young spikes was observed under an EMZ-TR dissecting microscope. The following measurements were recorded: the morphological characteristics of florets at different developmental stages, the number of spikelets per spike, the total number of differentiated florets per spike, and the number of fertile florets per spike (florets containing stamen, ovary, stigmatic branch, and stigmatic hair).

\subsubsection{Measurements of Dry Matter in Spike and Non-Spike Organs}

Twenty plants with uniform growth were selected in each treatment at each stage. Plants were separated into leaf, stem, sheath, and spike, which were then deactivated at $105^{\circ} \mathrm{C}$ for $30 \mathrm{~min}$ and dried at $80^{\circ} \mathrm{C}$ until reaching a constant weight. The dry weight of each tissue type was measured.

\subsubsection{Measurements of Soluble Sugar and Sucrose Contents}

A sample (50 mg) was weighed and transferred to a $10 \mathrm{~mL}$ centrifuge tube, and $4 \mathrm{~mL}$ of $80 \%$ ethanol was then added. The tube was heated in an $80^{\circ} \mathrm{C}$ water bath for $40 \mathrm{~min}$ and then centrifuged $10 \mathrm{~min}$ to collect the supernatant. Ethanol $(2 \mathrm{~mL})$ was added to the residual pellet, and the tube was centrifuged again to collect the supernatant. This step was repeated twice, and the supernatants were combined into one tube, which were added by activated carbon $(10 \mathrm{mg})$. The mixture was heated at $80^{\circ} \mathrm{C}$ for $30 \mathrm{~min}$ for decolorization, which was then adjusted to $10 \mathrm{~mL}$ by ethanol. Tubes were centrifuged $10 \mathrm{~min}$ to collect the supernatant for measurement. The anthrone-sulphuric acid method was used for measuring the soluble sugar content, and the resorcinol method was used for measuring the sucrose content [28].

\subsubsection{Measurements of Cytokinin and Auxin Contents}

Fresh young spike tissues were harvested from each treatment at each stage and cryopreserved at $-80{ }^{\circ} \mathrm{C}$. Cytokinin and auxin contents were measured by ELISA as described in Wang et al. [29].

\subsubsection{Measurements of Yield and Yield Components}

At the mature stage, spike number per unit area was estimated by counting the number of plants in two rows of one meter length. Thirty plants from each treatment were selected randomly for the measurement of grain number per spike. Grain yield was estimated from wheat yield in $4 \mathrm{~m}^{2}$ of each treatment, and grain samples were selected randomly to measure thousand grain weight.

\subsection{Formulae for Calculations}

Fertile floret setting rate $=$ number of grains/number of fertile florets

Spikelet setting rate $=$ number of spikelets that bear grains/total number of spikelets

Increasing rate of sugar content $=$ (sugar content in 6-BA treatment - sugar content in the control)/sugar content in the control

\subsection{Statistical Analysis}

The results of the experiment in two growing seasons showed similar patterns, allowing the mean value of the two seasons to be presented in the figures and tables. Experimental data were analyzed and processed using Microsoft Office 2016. The linear regression analysis was made using Origin 2017 by fitting the line, to judge whether the linear model equations of degradation and abortion stage accord with the dynamic process of descending linear pattern and gradually descending linear pattern and to observe the changes in degradation rate and abortion rate of the 6-BA treatment. Graphs were made 
in Origin 2017. Variance analysis was carried out using Duncan's multiple range test at a significance level of 5\% to compare the mean values of the different treatments and Pearson's correlation analysis at $p<0.05$ and $p<0.01$ was to assess the degree of relationships between variables (determine which physiological index is more closely related to the floret development) using SPSS version 24.0.

\section{Results and Analysis}

\subsection{The Effects of 6-BA Application on the Dynamics of Floret Development in Wheat}

As shown in Figure 1, the dynamics of the number of florets per spike with two treatments in the two varieties shared a similar pattern that could be divided into the degeneration stage $(0 \mathrm{~d}-6 \mathrm{~d})$ and the abortion stage $(6 \mathrm{~d}-20 \mathrm{~d})$. In the degeneration and abortion stages, the number of florets changed in a rapid descending linear pattern and a gradually descending linear pattern, respectively. The number of differentiated florets in each stage had the following order: V1S1 > V1S0 > V2S1 > V2S0. The two-year 6-BA application effectively decreased the number of florets degenerated and aborted in V1 and V2 by 2.75 and 2.34, respectively. These results indicated that the degeneration rate of florets and the abortion rate of fertile florets were reduced, the number of differentiated florets was increased, and the number of fertile florets aborted was decreased after the application of 6-BA.

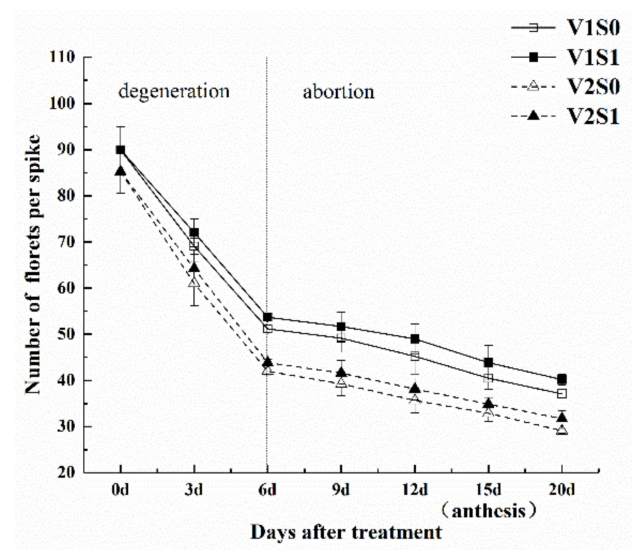

Figure 1. Dynamics of floret development under exogenous 6-BA treatment and the control in wheat. The effects of 6-BA on the number of florets per spike during 2016-2018. Significant at ${ }^{*} p=0.05$, ** $p=0.01$. Note: V1S0: Zhoumai 16 with control treatment; V1S1: Zhoumai 16 sprayed with 6-BA; V2S0: Yumai 49-198 with control treatment; V2S1: Yumai 49-198 sprayed with 6-BA. Model Equations: V1S0: degeneration: $y=-19.415 x+108.92, R^{2}=0.998^{* *}$, abortion: $y=-3.6835 x+55.685, R^{2}=0.9853^{* *}$; V1S1: degeneration: $y=-18.168 x+108.22, R^{2}=1 * *$, abortion: $y=-3.4835 x+58.118, R^{2}=0.9728^{* *}$; V2S0: degeneration: $y=-21.625 x+106, R^{2}=0.9951^{* *}$, abortion: $y=-3.2165 x+45.433, R^{2}=0.997^{* *}$; V2S1: degeneration: $y=-20.708 x+105.86, R^{2}=0.9999^{* *}$, abortion: $y=-3.092 x+47.311, R^{2}=0.9959^{* *}$.

\subsection{The Effects of 6-BA Application on the Number of Fertile Florets and the Number of Grains in Wheat}

Figure 2A shows that there were significant differences in the number of fertile florets per spike and the grain number per spike between V1S1 and V1S0 as well as between V2S1 and V2S0 over the two years. The number of fertile florets per spike had an increase of 2.50 in VIS1 compared to V1S0 and an increase of 1.84 in V2S1 compared to V2S0. The grain number per spike had an increase of 3.51 in V1S1 compared to V1S0 and an increase of 2.83 in V2S1 compared to V2S0. As shown in Figure 2B, the treatments sprayed with 6-BA of two varieties both had a significant increase in the fertile floret setting rate and the spikelet setting rate compared to S0. V1S1 had a $3.28 \%$ increase in the fertile floret setting rate, while V2S1 had a 3.65\% increase. For the spikelet setting rate, V1S1 increased by $4.57 \%$, while V2S1 increased by $3.35 \%$. In summary, the number of fertile florets, floret setting rate and spikelet setting rate were all increased under the exogenous 6-BA application, which ultimately increased the grain number per spike. 

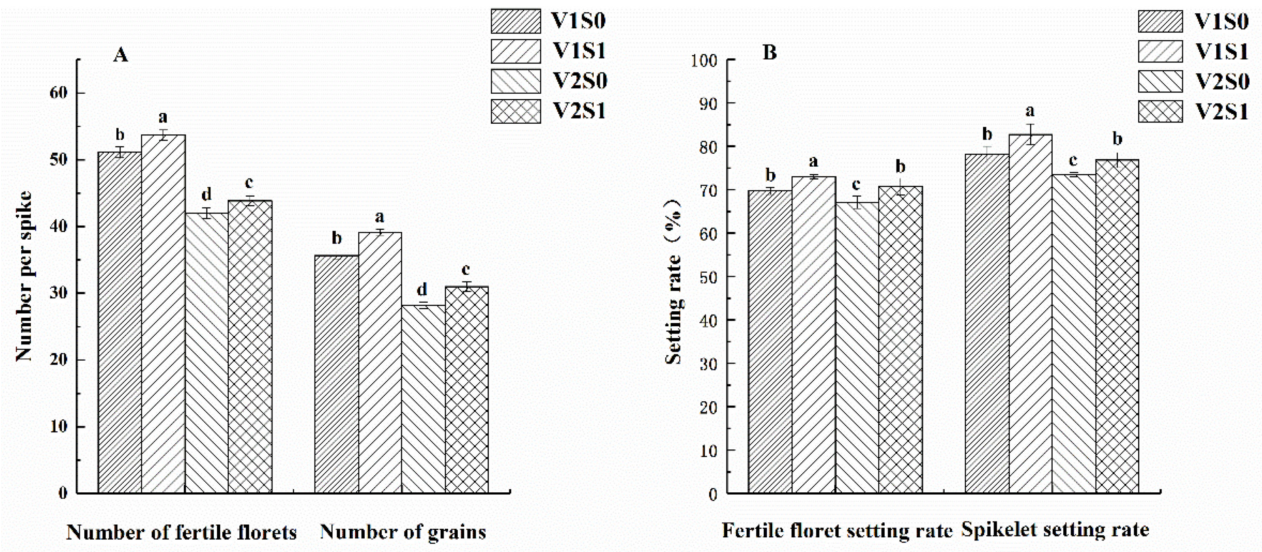

Figure 2. Differences of fertile floret grain setting characteristics under exogenous 6-BA treatment and the control in wheat. Different lowercase letters above the column for the same item of the abscissa axis indicate significant differences $(p<0.05)$. The effects of 6-BA on the number of fertile florets and grains during 2016-2018 (A). The effects of 6-BA on fertile floret setting rate and spikelet setting rate during 2016-2018 (B).

3.3. The Effects of 6-BA Application on the Accumulation and Distribution of Dry Matter in the Spike and Non-Spike Organs in Wheat

As shown in Figure 3A,B, the dry matter accumulation in spike and non-spike organs of both varieties gradually increased as the growth period progressed from $0 \mathrm{~d}$ (the day of the application) to $20 \mathrm{~d}$ (5 days after anthesis). Compared to S0, the dry weight of spike and non-spike organs were higher of 6-BA application at each stage, and V1S1 had a larger increase. That suggests exogenous 6-BA may promote the dry weight of spike and non-spike organs to increase. Figure 3C shows that the ratio of spike dry weight/culm dry weight continuously increased from $0 \mathrm{~d}$ to $20 \mathrm{~d}$ and that this ratio was higher in the S1 treatment than S0. In addition, the increase of the spike dry weight/culm dry weight ratio between V1S1 and V1S0 was larger than that between V2S1 and V2S0. In summary, the ratio of spike dry weight/culm dry weight of the 6-BA application was increased, and exogenous 6-BA promoted the transport of dry matter from non-spike organs to the spike and increased the dry matter accumulation in the spike. Furthermore, exogenous 6-BA had a greater influence on the large-spike variety V1.

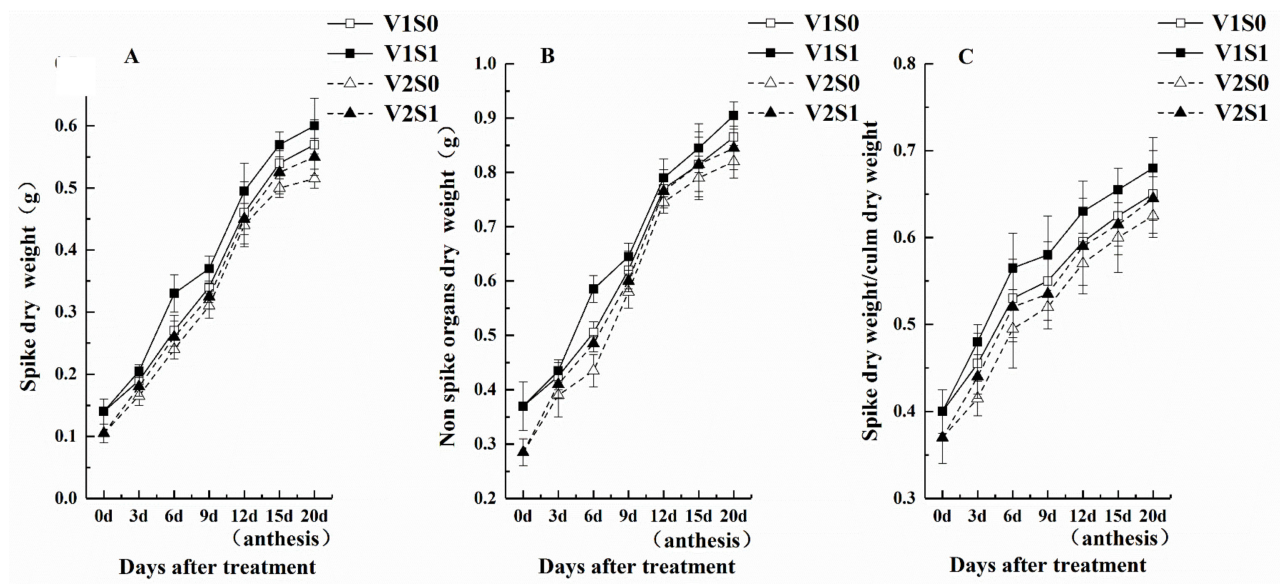

Figure 3. Differences of dry matter accumulation in spike and non-spike organs under exogenous 6-BA treatment and the control in wheat. The effects of 6-BA on spike dry weight (A), non-spike organs dry weight (B), and dry weight in spike/culm (C) during 2016-2018, respectively. 


\subsection{Effects of 6-BA Application on Sugar Content in Different Organs During Anthesis in Wheat}

Figure $4 \mathrm{~A}$ shows that 6-BA application resulted in a negative value of the increasing rate of soluble sugar in leaf, stem, and sheath for the two varieties compared to S0. However, the soluble sugar in the spike was increased by $26.81 \%$ and $22.81 \%$ in V1 and V2, respectively. The decreasing rate of soluble sugar content in leaf, stem, and sheath as well as the increasing rate of soluble sugar content in the spike were higher in V1 than in V2, indicating that the soluble sugar content in different organs of different varieties responded to 6-BA differently. Figure 4B shows that after 6-BA application, the sucrose content in different organs exhibited a similar pattern as that of the soluble sugar content. The sucrose content decreased in the leaf, stem, and sheath of two varieties but increased in the spike at $27.38 \%$ and $25.10 \%$ in V1 and V2, respectively. In summary, exogenous 6-BA promoted the transport of soluble sugar and sucrose from leaf, stem, and sheath to spike and increased the sugar contents in spike.
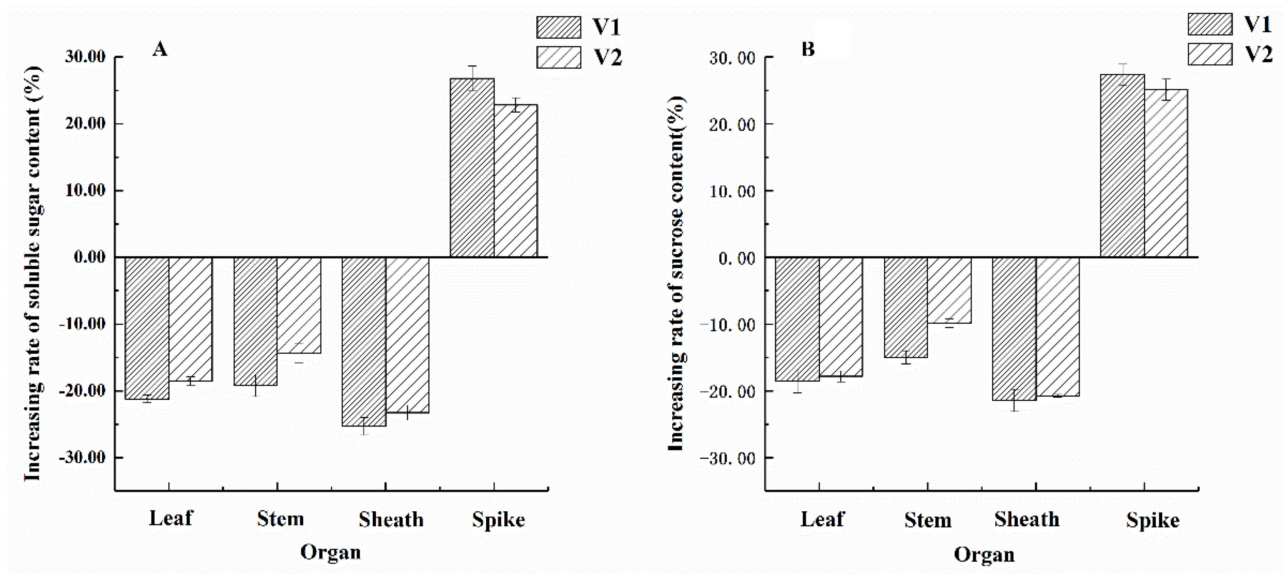

Figure 4. Changes of soluble sugar and sucrose contents in different organs at anthesis under exogenous 6-BA treatment and the control in wheat. The effects of 6-BA on soluble sugar content (A) and sucrose content (B) during 2016-2018, respectively.

\subsection{The Effects of 6-BA Application on Endogenous Hormone Content in Spikes}

Figure $5 \mathrm{~A}$ shows that the auxin content in the spikes of the two varieties fluctuated from $0 \mathrm{~d}$ to $20 \mathrm{~d}$. There was a slight increase in auxin content at anthesis, which is beneficial for the development of fertile florets. After anthesis, the auxin content dropped to the lowest level. In the abortion stage of fertile florets, the auxin content in the spike followed patterns of V1S1 < V1S0 and V2S1 < V2S0, indicating that a low level of auxin at this stage was helpful for fertile florets to survive. At anthesis, the auxin content in the two varieties exhibited a pattern of $\mathrm{S} 1>\mathrm{S} 0$, suggesting that 6-BA application was favourable for auxin biosynthesis in the spike at anthesis and may promote flowering. Figure $5 \mathrm{~B}$ shows that the cytokinin content in the spike treated with $\mathrm{S} 0$ and 6-BA of both varieties exhibited a similar pattern. From $0 \mathrm{~d}$ to $20 \mathrm{~d}$, the cytokinin content fluctuated by first increasing and then decreasing. From $0 \mathrm{~d}$ to $6 \mathrm{~d}$ of the floret degeneration stage, the CTK content first increased and then decreased. At $9 \mathrm{~d}$, the CTK content reached its peak level followed by another fluctuation. At $15 \mathrm{~d}$ (anthesis), the CTK level was a small peak. The CTK content at each stage was higher treated with 6-BA application compared to S0 treatment in both varieties. At anthesis, the CTK content had an increase of $0.03 \mathrm{ug} \cdot \mathrm{g}^{-1} \mathrm{FW}$ and $0.01 \mathrm{ug} \cdot \mathrm{g}^{-1} \mathrm{FW}$ in V1 and V2, respectively. In summary, after exogenous 6-BA application, the auxin content in the spike was decreased during the fertile floret abortion stage and increased at anthesis, the cytokinin content was increased in the fertile floret abortion stage. In comparison, exogenous 6-BA had a greater influence on the large-spike variety V1 and provided a physiological basis for increasing the setting rate and forming large spikes. 

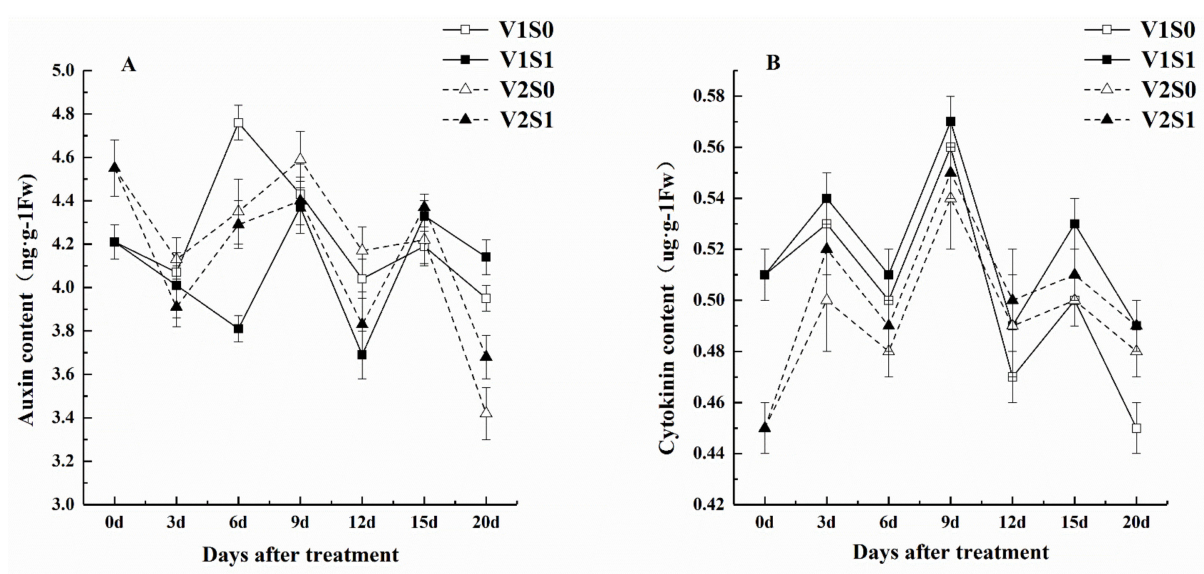

Figure 5. Changes of auxin and cytokinin contents in the spike under exogenous 6-BA treatment and the control in wheat. The effects of 6-BA on auxin content (A) and cytokinin content (B) during 2016-2018, respectively.

3.6. Relationships Among Spike Dry Matter, Sugars, Hormones, and the Number of Florets per Spike and Grain Number per Spike at Anthesis

Table 1 shows that spike dry weight and contents of soluble sugar, sucrose, auxin, and cytokinin were all positively correlated with the number of fertile florets per spike at anthesis. Spike dry weight and contents of soluble sugar, sucrose, and cytokinin reached a highly significant level. Grain number per spike exhibited positive correlations with spike dry weight and contents of soluble sugar, sucrose, auxin, and cytokinin. The correlations of grain number per spike with spike dry weight and cytokinin reached a highly significant level, and its correlations with soluble sugar content and sucrose content were significant. These results indicated that increasing spike dry weight as well as the contents of sugar, auxin, and cytokinin at anthesis could increase the number of fertile florets per spike, therefore promoting grain setting.

Table 1. Relationships among spike dry weight, sugar content, hormone content, and number of fertile florets per spike and grain number per spike at anthesis for two growing seasons of 2016-2018 $(n=6)$. Significant at ${ }^{*} p=0.05,{ }^{* *} p=0.01$.

\begin{tabular}{|c|c|c|c|c|c|}
\hline Variable & $\begin{array}{c}\text { Dry Weight } \\
\text { (g) }\end{array}$ & $\begin{array}{c}\text { Soluble Sugar } \\
\left(\mathrm{mg} \cdot \mathrm{g}^{-1} \mathrm{DW}\right)\end{array}$ & $\begin{array}{c}\text { Sucrose } \\
\left(\mathrm{mg} \cdot \mathrm{g}^{-1} \mathrm{DW}\right)\end{array}$ & $\begin{array}{c}\text { Auxin } \\
\left(\text { ng. } \text { g }^{-1} \mathrm{FW}\right)\end{array}$ & $\begin{array}{c}\text { Cytokinin } \\
\left(\text { ug } \cdot \mathrm{g}^{-1} \mathrm{FW}\right)\end{array}$ \\
\hline $\begin{array}{l}\text { Number of fertile florets } \\
\text { per spike }\end{array}$ & $0.63^{* *}$ & $0.50^{* *}$ & $0.59 * *$ & 0.34 & $0.65^{* *}$ \\
\hline Grain number per spike & $0.60 * *$ & $0.47 *$ & 0.51 * & 0.17 & $0.55^{* *}$ \\
\hline
\end{tabular}

\subsection{The effects of 6-BA Application on the Developmental Morphological Characteristics of Fertile Florets and} Grains in Wheat

Figure 6 shows that on $6 \mathrm{~d}$ after 6-BA application, floret 4 was fertile in the S1 treatment but infertile in the S0 treatment and that the pistils and stamens in florets 1, 2, and 3 were all larger than those in the control treatment. During anthesis, floret 4 in the S1 treatment was fertile and its ovary spread outwards, which was well developed to flower and capable of becoming grains. Floret 4 in the S0 was already atrophied and aborted, which then could not develop into grains. The ovary sizes of florets 1 , 2 , and 3 were larger in the S1 treatment than those in the control. On $5 \mathrm{~d}$ after anthesis, the results are the same as the anthesis and the fertile florets continued to develop into grains. These results indicated that foliar application of 6-BA increases the number of fertile florets and promotes the development and grain setting of the fertile florets. 

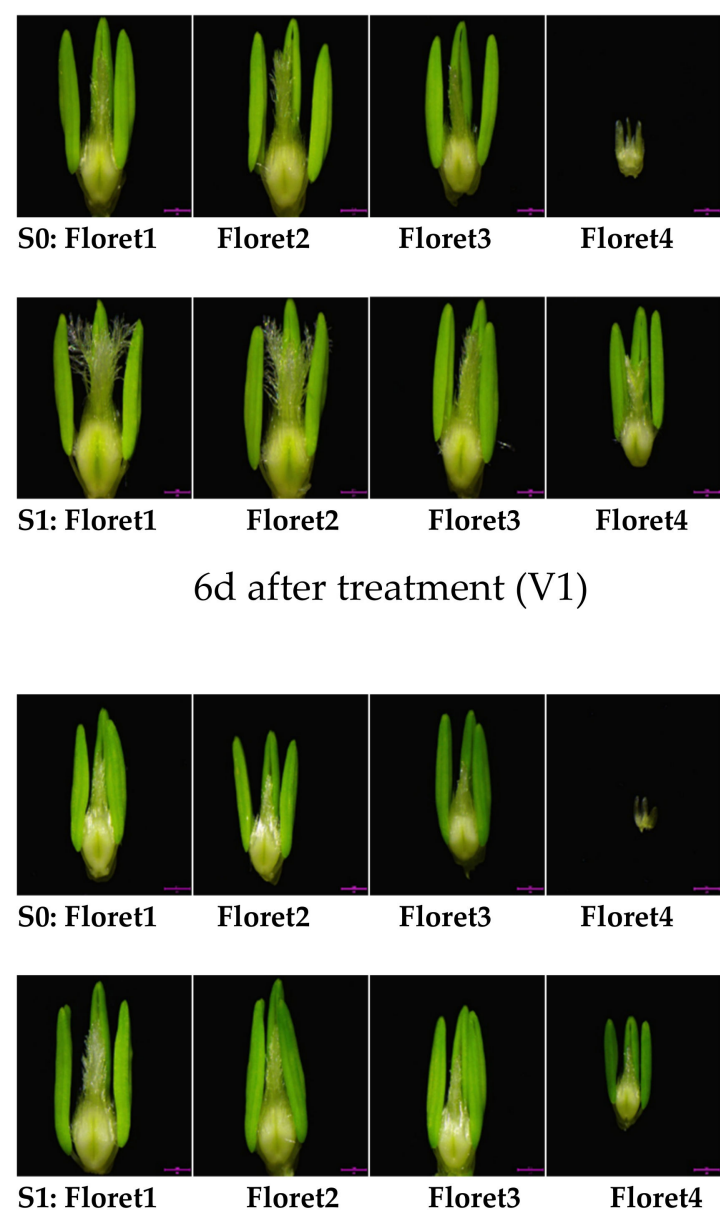

$6 \mathrm{~d}$ after treatment (V2)
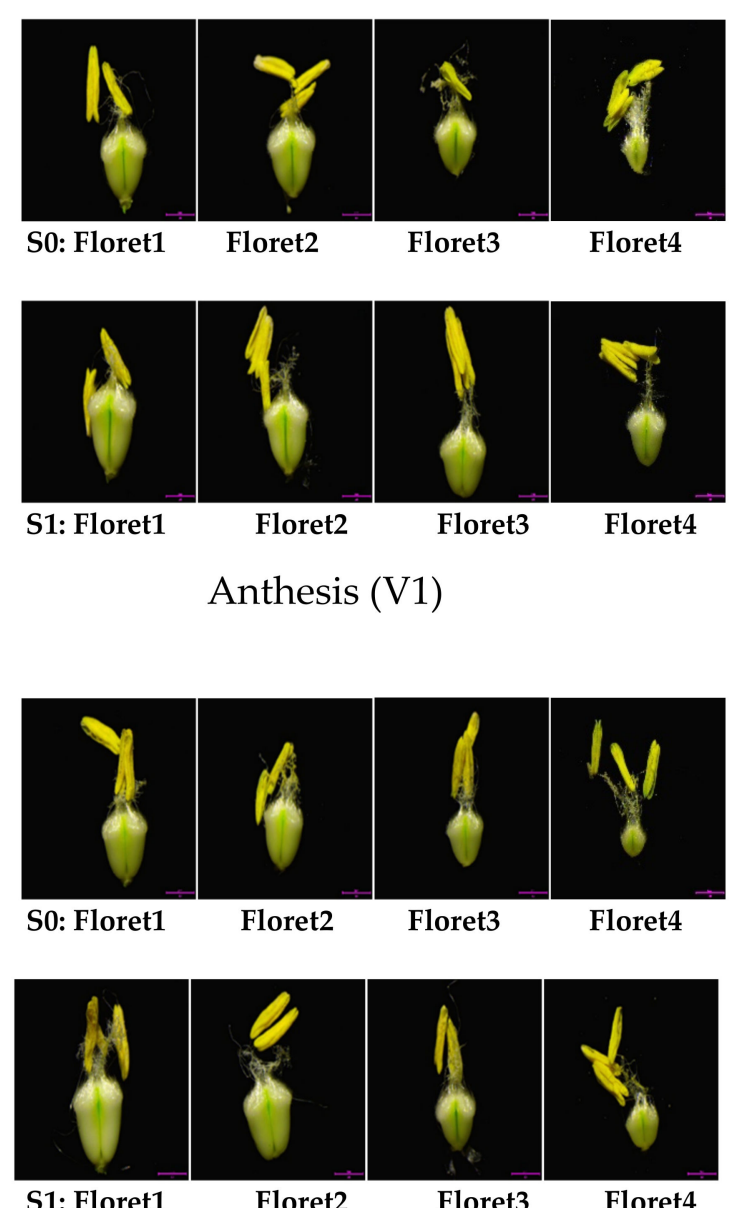

Anthesis (V2)
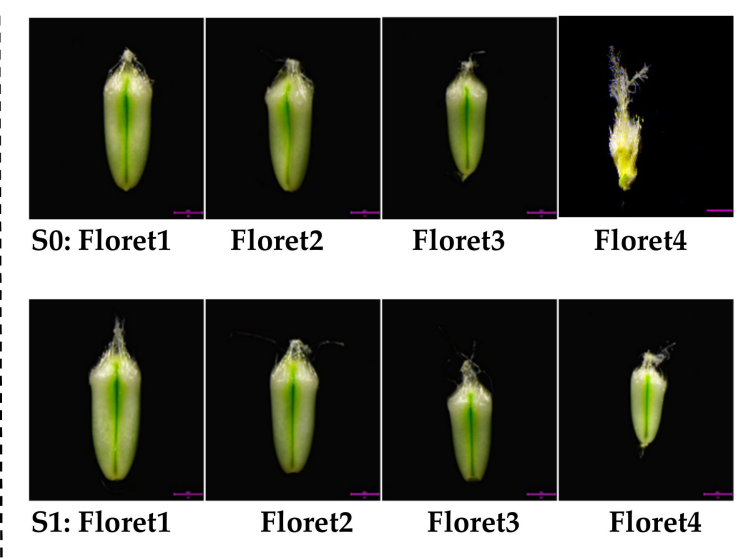

$5 \mathrm{~d}$ post-anthesis (V1)
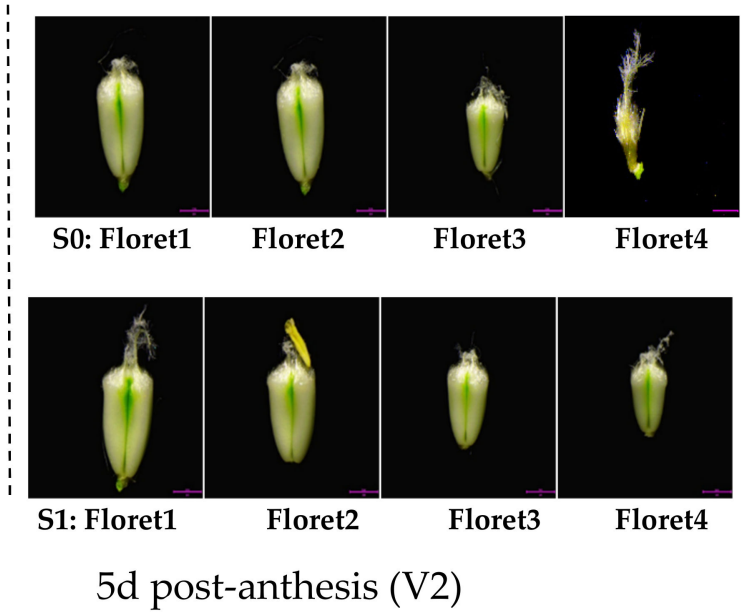

Figure 6. Differences in the development characteristics and likelihood of grain set in different floret positions under exogenous 6-BA treatment and the control. Images using floret 1, floret 2, floret 3, and floret 4 of spikelet 9 (Figure S1) that attributed the middle part of the spike. 


\subsection{Effects of 6-BA Foliar Application on Yield and Yield Components in Wheat}

The timing of 6-BA application was relatively late, the $\mathrm{SN}$ was already established around the jointing stage (Table 2). Therefore, 6-BA did not have a great effect on the SN. The SN had no significant difference between $\mathrm{S} 1$ treatment and $\mathrm{S} 0$ for both varieties. However, the SN in V2 was higher than that in V1 because V2 is a multiple-spike variety. There was a significant difference in GN between V1S1 and V1S0 as well as between V2S1 and V2S0. Compared to S0, 6-BA treatments of V1 and V2 during the two years ranged of increase in GN of 3.34-3.67 and 2.66-3.00, respectively. These results suggested that exogenous 6-BA significantly increases the GN in wheat. After 6-BA application in both varieties, the TGW was higher compared to the $\mathrm{S} 0$ treatment, but the difference was not significant. The GY of both varieties with 6-BA application in the two years was significantly greater than the S0 treatment. V1 had a yield increase of 327.53, and V2 had a yield increase of 273.78. Overall, exogenous 6-BA achieved a yield increase mainly by increasing the GN.

Table 2. Differences of yield and yield components under exogenous 6-BA treatment and the control in wheat.

\begin{tabular}{cccccc}
\hline Year & Treatment & SN & GN & TGW & GY \\
\hline \multirow{5}{*}{$2016-2017$} & V1S0 & $457.67^{\mathrm{b}}$ & $35.33^{\mathrm{b}}$ & $41.31^{\mathrm{a}}$ & $6954.63^{\mathrm{b}}$ \\
& V1S1 & $464.84^{\mathrm{b}}$ & $38.67^{\mathrm{a}}$ & $42.74^{\mathrm{a}}$ & $7214.88^{\mathrm{a}}$ \\
& V2S0 & $545.70^{\mathrm{a}}$ & $27.67^{\mathrm{d}}$ & $36.85^{\mathrm{b}}$ & $6344.48^{\mathrm{d}}$ \\
& V2S1 & $551.38^{\mathrm{a}}$ & $30.33^{\mathrm{c}}$ & $38.11^{\mathrm{b}}$ & $6541.70^{\mathrm{c}}$ \\
\hline \multirow{5}{*}{ 2017-2018 } & V1S0 & $513.66^{\mathrm{b}}$ & $36.00^{\mathrm{b}}$ & $47.35^{\mathrm{a}}$ & $7355.59^{\mathrm{b}}$ \\
& V1S1 & $529.49^{\mathrm{b}}$ & $39.67^{\mathrm{a}}$ & $48.77^{\mathrm{a}}$ & $7750.39^{\mathrm{a}}$ \\
& V2S0 & $615.36^{\mathrm{a}}$ & $28.67^{\mathrm{d}}$ & $42.76^{\mathrm{b}}$ & $6816.70^{\mathrm{c}}$ \\
& V2S1 & $622.03^{\mathrm{a}}$ & $31.67^{\mathrm{c}}$ & $43.71^{\mathrm{b}}$ & $7167.03^{\mathrm{b}}$ \\
\hline
\end{tabular}

Note: SN: spike number $\left(\times 10^{4} \mathrm{hm}^{-2}\right)$; GN: grain number per spike; TGW: thousand grain weight (g); GY: Grain yield $\left(\mathrm{kg} \mathrm{hm}^{-2}\right)$. Different superscript letters following values within a column indicate significant differences at the 0.05 probability level (Duncan's method; $n=3$ ).

\section{Discussion}

Studying developmental characteristics during the floret degeneration and abortion stage has great significance in promoting floret development, which further increases the GN [30,31]. Studies showed that spraying exogenous 6-BA increases the division rate and the number of endosperm cells and promotes the enlargement of floral organs, especially the ovule [20,32]. In the present study, after the foliar application of 6-BA during the peak of the floret degeneration stage, the abortion rate of fertile florets was reduced, the development of floral organs was promoted, and the number of fertile florets and grains per spike were increased, which eventually led to a significant yield increase. Therefore, understanding the physiological mechanism that determines the floret development is of great significance. Floret primordia develop mostly coinciding with stem elongation, when the distribution of nutrients from the vegetative to reproductive organs affects floret development, and a lack of available resources in the spike may promote floret degeneration and abortion [33-35]. In addition, the accumulation of soluble sugar and sucrose in the spike improves the differentiation and formation of the spike, providing sufficient support for floret development $[36,37]$. During the abortion stage of fertile florets, effective regulatory measures can be taken to increase the dry weight and the endogenous sugar contents of the spike, which would promote floret develop into grains. In the present study, 6-BA application promoted dry matter accumulation in the spike and non-spike organs as well as stimulated sugar transport from non-spike organs to the spike. At anthesis, the contents of soluble sugar and sucrose in the spike were increased and the sugar contents in non-spike organs including the leaf, stem, and sheath were reduced under the 6-BA application, which then increased the ratio of spike dry weight/culm dry weight and raised the proportion of dry matter distributed to the spike, thereby providing sufficient nutrient support for floret development.

Fertile floret development and grain setting are influenced by endogenous hormones. Previous studies have shown that floret abortion is correlated with endogenous cytokinin and auxin. In addition, the number of florets per spike is positively correlated with the level of endogenous cytokinin, and the 
effect of auxin is more complex [38,39]. The present study showed that the contents of auxin and cytokinin in the spike were both positively correlated with the number of fertile florets and grains per spike at anthesis. Increasing auxin and cytokinin contents in the spike at anthesis may induce flowering and promote floret survival to produce grains. In addition, auxin and cytokinin have a complementary effect during the early stages of female gametophyte development and an antagonistic effect during the formation of tetrads, which may lead to a negative correlation between auxin content and the number of fertile florets per spike in the abortion stage [40-43]. Exogenous 6-BA may inhibit auxin transport out of the early differentiated florets by raising the level of endogenous cytokinin, therefore weakening the negative effect of auxin and further increasing the GN $[44,45]$. The present study showed that an excess auxin level in the fertile floret abortion stage before anthesis was not favorable to develop and seed for fertile florets. During the abortion stage, exogenous 6-BA significantly increased the cytokinin content and reduced the auxin content in the spike, which decreased the negative effect of auxin content in the spike on the number of fertile florets per spike. Moreover, the effects further reduced the percentage of fertile florets that fail to develop into grains, providing a physiological basis for the development of fertile florets becoming grains and eventually increasing the number of fertile florets and grain number, which achieved a higher yield. Compared to the multiple-spike variety (Yumai 49-198), 6-BA had a greater effect in the large-spike variety (Zhoumai 16).

\section{Conclusions}

This study investigated the effects of 6-BA on floret development and grain setting in the Chinese wheat cultivar Zhoumai 16 and Yumai 49-198. The results have demonstrated that, before the abortion of fertile florets in wheat (the stage when a portion of fertile florets die without forming grains), foliar spraying application of 6-BA have a positive effect on the development of fertile florets by acting on the physiological mechanism including dry matter, sugar and hormone, which provided a sufficient material basis for development and grain setting of the fertile florets. 6-BA application improved the number of fertile florets and final grain number by reducing the number of florets degenerated and the number of fertile florets aborted, which eventually achieved the goal of yield increase. In conclusion, 6-BA application is an efficient strategy for improving cereal yields.

Supplementary Materials: The following are available online at http://www.mdpi.com/2073-4395/9/9/546/s1, Figure S1. Floret positions in spikelet 9. Floret 1, floret 2, floret 3, floret 4 and floret $\mathrm{n}$ are represented by F1, F2, F3, F4 and Fn, respectively.

Author Contributions: Y.Z., and S.Z. designed the study; S.L. and M.S. performed the study; J.D., J.Y., contributed to analyze the data; S.L., Y.Z., and S.Z. wrote the manuscript; M.S. and J.D. assisted manuscript writing and editing. All of the authors contributed to the discussion of the results.

Funding: This research was funded by the National Natural Science Foundation of China [grant number 31571607].

Acknowledgments: We gratefully acknowledge the College of Agronomy, Henan Agricultural University, for providing the laboratory of this study. We sincerely thank the reviewers for their helpful comments and supplementary proposal. We also thank the native English speakers (AJE) who provided assistance with language correction.

Conflicts of Interest: The authors declare no conflict of interest.

\section{References}

1. Jiao, X.-Q.; Mongol, N.; Zhang, F.-S. The transformation of agriculture in China: Looking back and looking forward. J. Integr. Agric. 2018, 17, 755-764. [CrossRef]

2. Cuevas, J.; Daliakopoulos, I.N.; Del Moral, F.; Hueso, J.J.; Tsanis, I.K. A Review of Soil-Improving Cropping Systems for Soil Salinization. Agronomy 2019, 9, 295. [CrossRef]

3. Godfray, H.C.J.; Beddington, J.R.; Crute, I.R.; Haddad, L.; Lawrence, D.; Muir, J.F.; Toulmin, C.; Pretty, J.; Robinson, S.; Thomas, S.M. Food security: the challenge of feeding 9 billion People. Science 2012, 327, 812-818. [CrossRef] [PubMed] 
4. Duan, J.; Wu, Y.; Zhou, Y.; Ren, X.; Shao, Y.; Feng, W.; Zhu, Y.; He, L.; Guo, T. Approach to Higher Wheat Yield in the Huang-Huai Plain: Improving Post-anthesis Productivity to Increase Harvest Index. Front. Plant Sci. 2018, 9, 1457. [CrossRef] [PubMed]

5. McGuire, S. FAO, IFAD, and WFP. The State of Food Insecurity in the World 2015: Meeting the 2015 International Hunger Targets: Taking Stock of Uneven Progress; FAO: Rome, Italy, 2015. Adv. Nutr. 2015, 6, 623-624. [CrossRef] [PubMed]

6. Tyczewska, A.; Woźniak, E.; Gracz, J.; Kuczyński, J.; Twardowski, T. Towards Food Security: Current State and Future Prospects of Agrobiotechnology. Trends Biotechnol. 2018, 36, 1219-1229. [CrossRef] [PubMed]

7. Qin, X.; Zhang, F.; Liu, C.; Yu, H.; Cao, B.; Tian, S.; Liao, Y.; Siddique, K.H. Wheat yield improvements in China: Past trends and future directions. Field Crop. Res. 2015, 177, 117-124. [CrossRef]

8. Sadras, V.O.; Slafer, G.A. Environmental modulation of yield components in cereals: Heritabilities reveal a hierarchy of phenotypic plasticities. Field Crop. Res. 2012, 127, 215-224. [CrossRef]

9. Duan, J.; Wu, Y.; Zhou, Y.; Ren, X.; Shao, Y.; Feng, W.; Zhu, Y.; Wang, Y.; Guo, T. Grain number responses to pre-anthesis dry matter and nitrogen in improving wheat yield in the Huang-Huai Plain. Sci. Rep. 2018, 8, 7126. [CrossRef]

10. Acreche, M.M.; Briceño-Félix, G.; Sánchez, J.A.M.; Slafer, G.A. Physiological bases of genetic gains in Mediterranean bread wheat yield in Spain. Eur. J. Agron. 2008, 28, 162-170. [CrossRef]

11. Reynolds, M.; Foulkes, M.J.; Slafer, G.A.; Berry, P.; Parry, M.A.J.; Snape, J.W.; Angus, W.J. Raising yield potential in wheat. J. Exp. Bot. 2009, 60, 1899-1918. [CrossRef] [PubMed]

12. González, F.G.; Miralles, D.J.; Slafer, G.A. Wheat floret survival as related to pre-anthesis spike growth. J. Exp. Bot. 2011, 62, 4889-4901. [CrossRef] [PubMed]

13. Guo,Z.; Slafer, G.A.; Schnurbusch, T. Genotypic variation in spike fertility traits and ovary size as determinants of floret and grain survival rate in wheat. J. Exp. Bot. 2016, 67, 4221-4230. [CrossRef] [PubMed]

14. Cui, J.M.; Guo, T.C.; Zhu, Y.J.; Wang, C.Y.; Ma, X.M. Ear of Wheat, 1st ed.; China Agricultural Press: Beijing, China, 2008. (In Chinese)

15. Zheng, C.F.; Zhu, Y.J.; Wang, C.Y.; Guo, T.C. Wheat grain yield increase in response to pre-anthesis foliar application of 6-benzylaminopurine is dependent on floret development. PLoS ONE 2016, 11, e0156627. [CrossRef] [PubMed]

16. Gonzalez-Navarro, O.E.; Griffiths, S.; Molero, G.; Reynolds, M.P.; Slafer, G.A. Dynamics of floret development determining differences in spike fertility in an elite population of wheat. Field Crop. Res. 2015, 172, 21-31. [CrossRef]

17. Ferrante, A.; Savin, R.; Slafer, G.A. Floret development and grain setting differences between modern durum wheats under contrasting Nitrogen availability. J. Exp. Bot. 2013, 64, 169-184. [CrossRef] [PubMed]

18. Serrago, R.A.; Miralles, D.J.; Slafer, G.A. Floret fertility in wheat as affected by photoperiod during stem elongation and removal of spikelets at booting. Eur. J. Agron. 2008, 28, 301-308. [CrossRef]

19. Dreccer, M.F.; Wockner, K.B.; Palta, J.A.; McIntyre, C.L.; Borgognone, M.G.; Bourgault, M.; Reynolds, M.P.; Miralles, D.J. More fertile florets and grains per spike can be achieved at higher temperature in wheat lines with high spike biomass and sugar content at booting. Funct. Plant Boil. 2014, 41, 482-495. [CrossRef]

20. Bartrina, I.; Otto, E.; Strnad, M.; Werner, T.; Schmülling, T. Cytokinin Regulates the Activity of Reproductive Meristems, Flower Organ Size, Ovule Formation, and Thus Seed Yield in Arabidopsis thaliana [C][W][OA]. Plant Cell 2011, 23, 69-80. [CrossRef]

21. Jameson, P.E.; Song, J.C. Cytokinin: A key driver of seed yield. J. Exp. Bot. 2016, 67, 593-606. [CrossRef]

22. Zhang, K.R.; Diederich, L.; John, P. The Cytokinin Requirement for Cell Division in Cultured Nicotiana plumbaginifolia Cells Can Be Satisfied by Yeast Cdc25 Protein Tyrosine Phosphatase. Implications for Mechanisms of Cytokinin Response and Plant Development. Plant Physiol. 2004, 137, 308-316. [CrossRef] [PubMed]

23. Cai, T.; Meng, X.; Liu, X.; Liu, T.; Wang, H.; Jia, Z.; Yang, D.; Ren, X. Exogenous Hormonal Application Regulates the Occurrence of Wheat Tillers by Changing Endogenous Hormones. Front. Plant Sci. 2018, 9, 1886. [CrossRef] [PubMed]

24. Rivero, R.M.; Kojima, M.; Gepstein, A.; Sakakibara, H.; Mittler, R.; Gepstein, S.; Blumwald, E. Delayed leaf senescence induces extreme drought tolerance in a flowering plant. Proc. Natl. Acad. Sci. USA 2007, 104, 19631-19636. [CrossRef] [PubMed]

25. Yang, D.Q.; Li, Y.L.; Ni, Y.L.; Yin, Y.P.; Yang, W.B.; Cui, Z.Y.; Zhang, Y.T.; Ma, R.Y.; Wang, Z.L. Effects of Exogenous ABA and 6-BA on Protein Content and Grain Filling Process in Different Types of Stay-Green Wheat. Acta Agron. Sin. 2016, 40, 301-312. (In Chinese) [CrossRef] 
26. Yang, D.Q.; Luo, Y.L.; Dong, W.H.; Yin, Y.P.; Li, Y.; Wang, Z.L. Response of photosystem II performance and antioxidant enzyme activities in stay-green wheat to cytokinin. Photosynthetica 2018, 56, 567-577. [CrossRef]

27. Luo, Y.; Tang, Y.; Zhang, X.; Li, W.; Chang, Y.; Pang, D.; Xu, X.; Li, Y.; Wang, Z. Interactions between cytokinin and nitrogen contribute to grain mass in wheat cultivars by regulating the flag leaf senescence process. Crop. J. 2018, 6, 538-551. [CrossRef]

28. Shi, H.; Wang, B.; Yang, P.; Li, Y.; Miao, F. Differences in Sugar Accumulation and Mobilization between Sequential and Non-Sequential Senescence Wheat Cultivars under Natural and Drought Conditions. PLOS ONE 2016, 11, 0166155. [CrossRef]

29. Wang, W.; Hao, Q.; Tian, F.; Li, Q.; Wang, W. Cytokinin-Regulated Sucrose Metabolism in Stay-Green Wheat Phenotype. PLoS ONE 2016, 11, e0161351. [CrossRef]

30. Wang, Z.-Q.; Zhang, W.-Y.; Yang, J.-C. Physiological mechanism underlying spikelet degeneration in rice. J. Integr. Agric. 2018, 17, 1475-1481. [CrossRef]

31. Sreenivasulu, N.; Schnurbusch, T. A genetic playground for enhancing grain number in cereals. Trends Plant Sci. 2012, 17, 91-101. [CrossRef]

32. Yang, D.; Li, Y.; Shi, Y.; Cui, Z.; Luo, Y.; Zheng, M.; Chen, J.; Li, Y.; Yin, Y.; Wang, Z. Exogenous Cytokinins Increase Grain Yield of Winter Wheat Cultivars by Improving Stay-Green Characteristics under Heat Stress. PLoS ONE 2016, 11, e0155437. [CrossRef] [PubMed]

33. Miralles, D.J.; Richards, R.A.; Slafer, G.A. Duration of the stem elongation period influences the number of fertile florets in wheat and barley. Funct. Plant Boil. 2000, 27, 931. [CrossRef]

34. Prystupa, P.; Savin, R.; Slafer, G.A. Grain number and its relationship with dry matter, N and P in the spikes at heading in response to $\mathrm{N} \times \mathrm{P}$ fertilization in barley. Field Crops Res. 2004, 90, 245-254. [CrossRef]

35. Ghiglione, H.O.; Gonzalez, F.G.; Serrago, R.; Maldonado, S.B.; Chilcott, C.; Curá, J.A.; Miralles, D.J.; Zhu, T.; Casal, J.J. Autophagy regulated by day length determines the number of fertile florets in wheat. Plant J. 2008, 55, 1010-1024. [CrossRef] [PubMed]

36. Fang, S.; Gao, K.; Hu, W.; Snider, J.L.; Wang, S.; Chen, B.; Zhou, Z. Chemical priming of seed alters cotton floral bud differentiation by inducing changes in hormones, metabolites and gene expression. Plant Physiol. Biochem. 2018, 130, 633-640. [CrossRef] [PubMed]

37. Lebon, G.; Wojnarowiez, G.; Holzapfel, B.; Fontaine, F.; Vaillant-Gaveau, N.; Clément, C. Sugars and flowering in the grapevine (Vitis vinifera L.). J. Exp. Bot. 2008, 59, 2565-2578. [CrossRef] [PubMed]

38. Emery, R.J.N.; Ma, Q.F.; Atkins, C.A. The Forms and Sources of Cytokinins in Developing White Lupine Seeds and Fruits. Plant Physiol. 2002, 123, 1593-1604. [CrossRef] [PubMed]

39. Zhao, Y.D. Essential Roles of Local Auxin Biosynthesis in Plant Development and in Adaptation to Environmental Changes. Annu. Rev. Plant Biol. 2018, 69, 417-435. [CrossRef] [PubMed]

40. Chika, N.; Yoshi, O.; Shusei, S.; Tomohiko, K.; Satoshi, T.; Chiharu, U. Histidine Kinase Homologs That Act as Cytokinin Receptors Possess Overlapping Functions in the Regulation of Shoot and Root Growth in Arabidopsis. Plant Cell 2004, 16, 1365-1377.

41. Schaller, G.E.; Bishopp, A.; Kieber, J.J. The Yin-Yang of Hormones: Cytokinin and Auxin Interactions in Plant Development. Plant Cell 2015, 27, 44-63. [CrossRef]

42. Kinoshita-Tsujimura, K.; Kakimoto, T. Cytokinin receptors in sporophytes are essential for male and female functions in Arabidopsis thaliana. Plant Signal. Behav. 2011, 6, 66-71. [CrossRef] [PubMed]

43. Wei, Y.M.; Zheng, Y.L. The Influence of Phytohormone on the Duration of Spike Differentiation in Multispiklet Wheat. J. Triticeae Crop. 2000, 20, 35-38. (In Chinese)

44. Roitsch, T.; Ehneß, R. Regulation of source/sink relations by cytokinins. Plant Growth Regul. 2000, 32, $359-367$. [CrossRef]

45. Yang, D.; Dong, W.; Luo, Y.; Song, W.; Cai, T.; Li, Y.; Yin, Y.; Wang, Z. Effects of exogenous 6-BA on photosynthetic characteristics and endogenous hormone content in wheat leaves under two nitrogen application levels at seedling stage. Sci. Agric. Sin. 2017, 50, 3871-3884. (In Chinese)

(C) 2019 by the authors. Licensee MDPI, Basel, Switzerland. This article is an open access article distributed under the terms and conditions of the Creative Commons Attribution (CC BY) license (http://creativecommons.org/licenses/by/4.0/). 